Saudi Journal of Oral and Dental Research

Abbreviated Key Title: Saudi J Oral Dent Res

ISSN 2518-1300 (Print) |ISSN 2518-1297 (Online)

Scholars Middle East Publishers, Dubai, United Arab Emirates

Journal homepage: https://saudijournals.com

Case Report

\title{
A Rare Case of Parotid Gland Sialolith
}

\author{
Dr. Chikku Shaila John ${ }^{1 *}$, Dr. Deepak Daryani ${ }^{2}$, Dr. Uthkal MP${ }^{3}$, Dr. Nilofer J Adhiraja ${ }^{4}$, Dr. Davis Nadakkavukaran ${ }^{5}$, \\ Dr. M.S Balakrishna ${ }^{6}$ \\ ${ }^{1}$ Post Graduate Student Department of Oral Medicine And Radiology Malabar Dental College And Research Centre, Manoor Chekanoor Road, Mudur \\ P.O, Edappal, Malappuram, Pin Code 679578, Kerala, India \\ ${ }^{2}$ Professor\& Head, Department Of Oral Medicine and Radiology Malabar Dental College and Research Centre, Manoor Chekanoor Road, Mudur P.O, \\ Edappal, Malappuram, Kerala, India \\ ${ }^{3}$ Professor Department of Oral Medicine and Radiology Malabar Dental College and Research Centre, Manoor Chekanoor Road, Mudur P.O, Edappal, \\ Malappuram Kerala, India \\ ${ }^{4}$ Post Gradute Student Department of Oral Medicine and Radiology Malabar Dental College and Research Centre, Manoor Chekanoor Road, Mudur \\ P.O, Edappal, Malappuram Kerala, India \\ ${ }^{5}$ Assistant Professor Deparment of Oral and Maxillofacial Surgery Malabar Dental College and Research Centre, Manoor Chekanoor Road, Mudur P.O, \\ Edappal, Malappuram, Kerala, India \\ ${ }^{6}$ Professor Deparment of Oral And Maxillofacial Surgery Malabar Dental College And Research Centre, Manoor Chekanoor Road, Mudur P.O, \\ Edappal, Malappuram Pin Code 679578, Kerala, India
}

DOI: $10.36348 /$ sjodr.2020.v05i12.004

| Received: 29.11.2020 | Accepted: 12.12.2020 | Published: 16.12.2020

*Corresponding author: Dr. Chikku Shaila John

\section{Abstract}

Parotid gland sialolith is a very rare condition with symptoms of pain and infection in affected individuals (4- 10\%) caused due to any systemic diseases, bacterial infections, medications, abnormality in the secretion of gland etc. Here reporting a case of 28 year old male patient having calculi in his left parotid gland. Routine radiographic procedures and advanced modalities like ultrasonography, cone beam tomography confirmed the diagnosis then it is removed surgically without major complications.

Keywords: Sialolith, parotid, salivary gland, salivary gland dysfunction, calculi, sialolith removal.

Copyright () 2020 The Author(s): This is an open-access article distributed under the terms of the Creative Commons Attribution 4.0 International License (CC BY-NC 4.0) which permits unrestricted use, distribution, and reproduction in any medium for non-commercial use provided the original author and source are credited.

\section{INTRODUCTION}

Sialoliths are the main cause of obstruction to salivary gland leading to salivary ectasia and dilatation of gland. Frequency of formation of calculi in various glands as follows, submandibular glands (83-94\%), parotid (4- 10\%), sublingual (1-7\%) [1, 2]. Alkaline, viscous, mucus rich nature of saliva having higher percentage of calcium phosphates, the long and sinuous position of whartons duct, will cause stasis thereby submandibular salivary system become more prone for development of sialoliths than the parotid gland. Males are more commonly affected. Systemic diseases like gout, Sjogrens, medications like anticholinergic and antisialogogue drugs, any history of trauma, head and neck radiotherapy, elderly patients, Alzheimer's and Parkinsons disease, stroke, cystic fibrosis and renal dysfunction also cause sialolith formation [3, 6, 1, 7]. Management of the condition depends on the size and location and severity of symptoms. Smaller stones may be managed by conservative treatments mainly by hot compresses, massage, increased oral fluid intake and sialogogues like lemon. Surgical treatment is done mainly to prevent recurrent parotitis [4]. Most of the sialoliths are about $5 \mathrm{~mm}$ and which is above $10 \mathrm{~mm}$ should be reported as sialolith of unusual size $[8,10]$.

\section{CASE REPORT}

A healthy 28 year old young male patient presented to department of oral medicine and radiology with a chief complaint of pain and swelling in his left side of cheek since 3 months. Pain aggravates on consumption of food. Examination of face demonstrated diffused indurated left facial swelling measuring about roughly $1 \mathrm{~cm}$ in diameter situated antero posteriorly along the zygomatic arch and $2 \mathrm{~cm}$ inferior to outer canthus of eye. There is no localized rise in temperature overlying skin and it was tender on palpation. Intraoral examination revealed non tender, mobile swelling distal to 27 regions. No pus discharges from parotid papilla on milking of gland. IOPAR and OPG was taken which revealed calculus situated distal to 28.Ultrasound and CBCT was also done and diagnosed as left chronic parotid sialadenitis with sialolithiasis. Patient was given a course of oral antibiotics and referred for surgical excision after 3 days under local anesthesia. Calculi of $10 \mathrm{~mm}, 8 \mathrm{~mm}$ of 
diameter were removed and follow up done for a month. The patient recovered without many complications.

\section{INVESTIGATIONS}

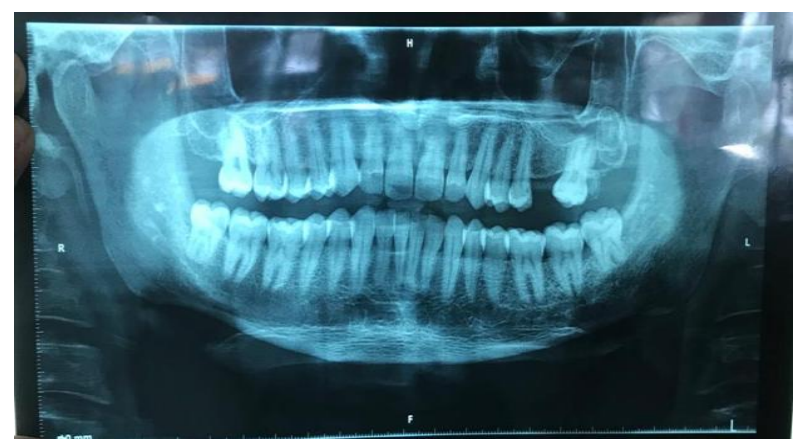

Fig-1: OPG revealing radiopaque structure distal to 27

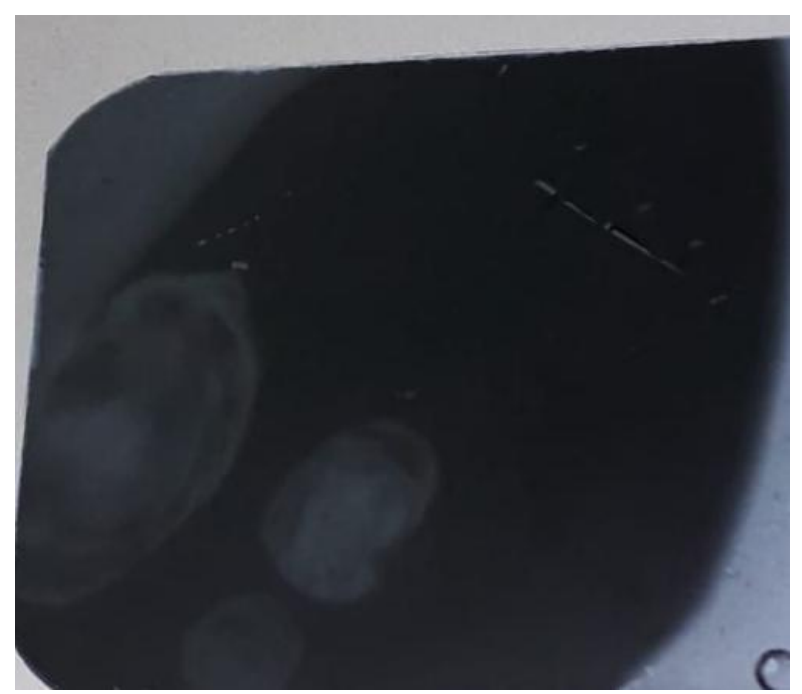

Fig-2: IOPAR showing multiple calculi

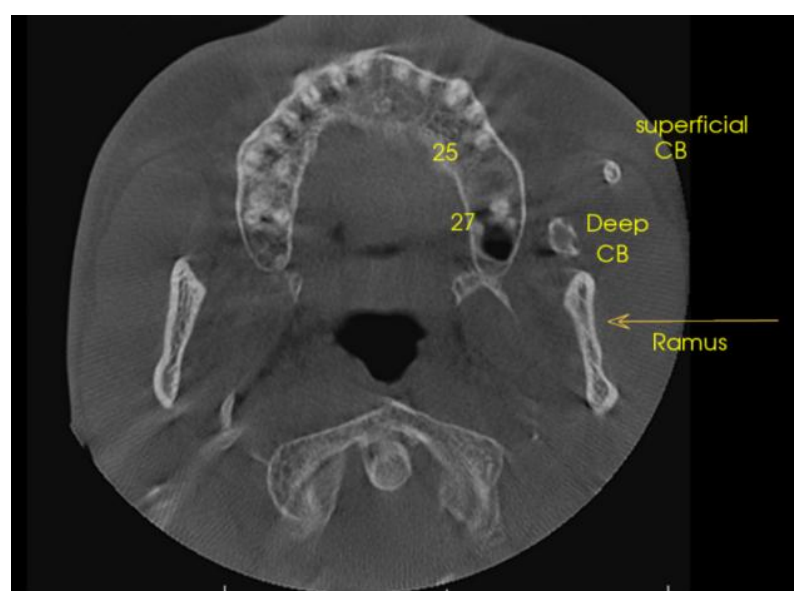

Fig-3: CBCT revealing localization of calcified masses,

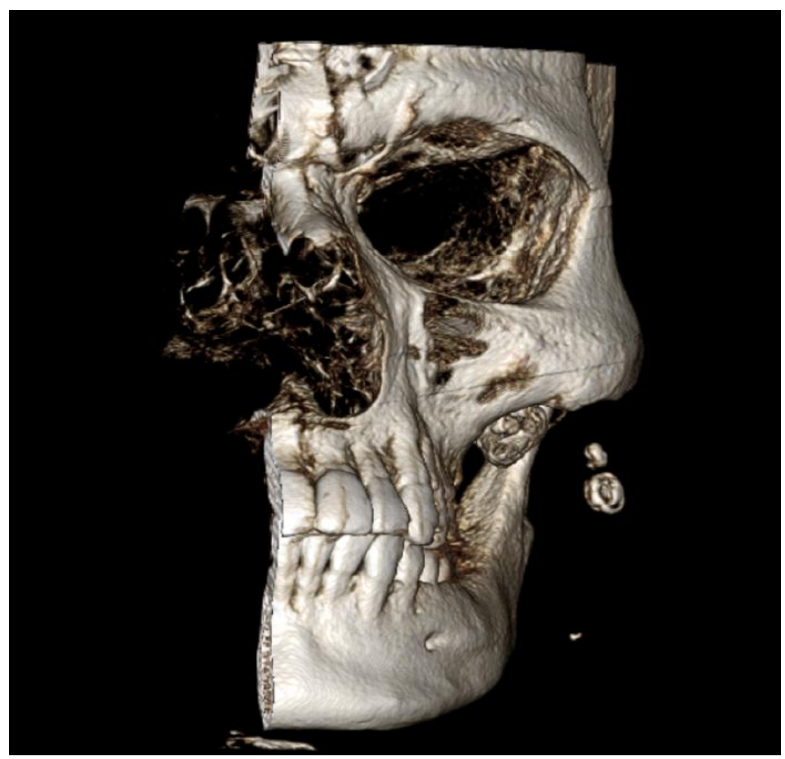

Fig-4: CBCT anterior view

Ultrasonography- impression - left chronic parotid sialadenitis with sialolithiasis blood investigations - unremarkable

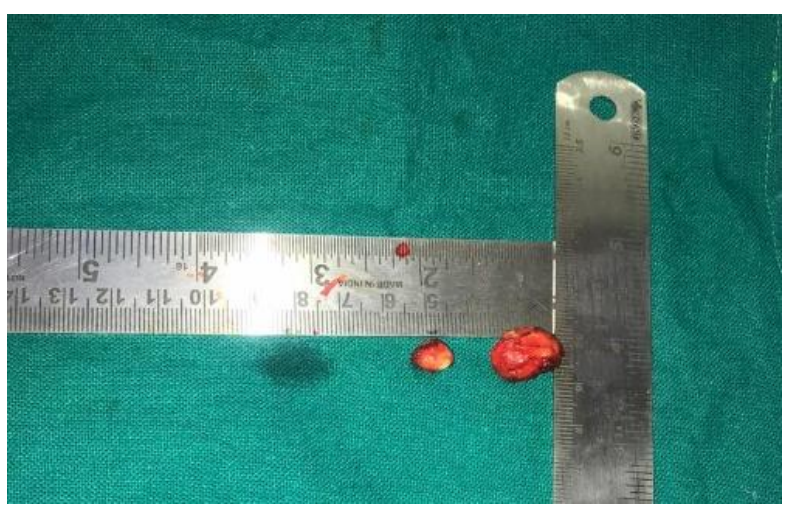

Fig-5: Calculi after surgical retrieval

\section{DISCUSSION}

Sialoliths in some cases are asymptomatic and diagnosed incidentally during routine radiographic examinations. Other symptoms are pain and swelling of the gland while eating and there will be gradual reduction of swelling [2]. On palpation, there will be feeling of small pebbles like structures [3]. Submandibular and parotid salivary stones have similar structures like amorphous, mineralized core surrounded by concentric layers of organic and inorganic material [5]. Ultrasonography is one of the standard aids used to diagnose sialoliths. Conventional sialography have risk of perforation to ducts and retrograde displacement of stone [9]. Sialoendoscopy, CT scan and MRI are other common diagnostic aids. In case of small calculi natural sialogogues can be given, drugs like pilocarpine and short wave infrared waves will cause contraction of ducts. Lithiotripsy is another option for glands not responding to conservative treatment and parotidectomy is the last treatment option [9]. 


\section{CONCLUSION}

Parotid gland sialoliths are rare. Ultrasonography along with radiographic investigations help in the diagnosis of sialoliths. There are various treatment options available for the management of sialoliths. Need of further researches are needed in diagnosing and managing this condition more effectively.

\section{REFERENCES}

1. Erdem, S., Abilov, A., Erdem, S., Zengin, A. Z., \& Sumer, M. (2018). An unusual parotid sialolith diagnosis and treatment: A. J Dent Res, 1(1), 1-4.

2. Debnath, S. C., \& Adhyapok, A. K. (2015). Sialolithiasis of an accessory parotid gland: an unusual case. British Journal of Oral and Maxillofacial Surgery, 53(7), 658-659.

3. Moghe, S., Pillai, A., Thomas, S., \& Nair, P. P. (2012). Parotid sialolithiasis. Case Reports, 2012, bcr2012007480.

4. Brown, K., Cheah, T., \& Ha, J. F. (2016). Spontaneous cutaneous extrusion of a parotid gland sialolith. Case Reports, 2016, bcr2016214887.

5. Kraaij, S., Karagozoglu, K. H., Kenter, Y. A., Pijpe, J., Gilijamse, M., \& Brand, H. S. (2015). Systemic diseases and the risk of developing salivary stones: a case control study. Oral surgery, oral medicine, oral pathology and oral radiology, 119(5), 539-543.

6. Ship, J. A. (2002). Diagnosing, managing, and preventing salivary gland disorders. Oral diseases, 8(2), 77-89.

7. Erdem, S., Abilov, A., Erdem, S., Zengin, A. Z., \& Sumer, M. (2018). An unusual parotid sialolith diagnosis and treatment: A. J Dent Res, 1(1), 1-4.

8. Batori, M., Mariotta, G., Chatelou, H., Casella, G., \& Casella, M. C. (2005). Diagnostic and surgical management of submandibular gland sialolithiasis: Report of a stone of unusual size. Eur Rev Med Pharmacol Sci, 9(1), 67-8.

9. Abdullah, O., \& AlQudehy, Z. (2016). Giant submandibular sialolith: A case report and literature review. Indian Journal of Otology, 22(2), 126.

10. Bhovi, T. V., Jaju, P. P., Ojha, S., \& Bhadouria, P. (2016). Giant submandibular sialolith in an old female patient: A case report and review of literature. Journal of Indian Academy of Oral Medicine and Radiology, 28(4), 437.

11. Gadipelly, S., Srilatha, T., Sheraz, B. S., \& Vijaykumar, N. (2016). Parotid Sialolith-A Case Report and Review of Literature. Int J Contemp Med Res, 3(4), 1211-3. 